CONGLOMERATE TUBERCLE AND COMBINED DEGENERATION OF THE CORD AS COMPLICATIONS OF VISCERAL TUBERCULOSIS *

\author{
PETER BASSOE, M.D.
}

CHICAGO

I. TUBERCUlosis OF TIIE SPINAL CORD

Occurrence and Pathology.-Excluding ordinary tuberculous meningitis and tuberculosis of the meninges due to extension from Pott's disease, tuberculosis of the cord is comparatively uncommon. As a feature of the extremely common disease, tuberculosis, it is decidedly rare, but considered in connection with the relatively rare syndrome of spinal cord tumor, it is fairly common. Thus, among 213 cases of cord tumor collected by Edward Flatau ${ }^{1}$ tubercle ranked first among the 58 cases of intramedullary tumor, glioma being second with 14 and sarcoma third with 13. Carl Doerr ${ }^{2}$ in his paper of 1911, however, was only able to collect 74 cases, adding only 12 from the literature to the 62 in Schlesinger's ${ }^{3}$ monograph of 1898, and two new ones.

Aside from a few cases of acute tuberculous meningomyelitis, practically all cases are instances of tumor-like "solitary," more properly conglomerate tubercle, and usually are due to infection of the interior of the cord by way of the blood stream, or, more rarely, to extension along the lymphatics in cases of meningeal tuberculosis. Doerr says that in three-fourths of all cases of conglomerate tuberculosis of the cord there has been present a tuberculous spinal meningitis which sometimes was the consequence and sometimes the result of the intramedullary tuberculosis. In 72 of the 76 cases the region affected was stated: Cervical 22, thoracic 15, lumbar 32, sacral 3 . Contrary to expectation, the cord affection is much less frequently secondary to tuberculosis of the spinal column and meninges than to tuberculosis of the lungs, joints and bones other than the vertebrae. A few authors have asserted that their cases were instances of primary localization of the tubercle bacillus in the cord, but this obviously is improbable in itself and is not considered proved by Doerr.

* Submitted for publication Jan. 10, 1918.

* From the Presbyterian Hospital.

* Read before the Chicago Society of Internal Medicine May 28, 1917.

1. Flatau, Edward: Handbuch der Neurologie, 1911, 2, 641.

2. Doerr, Carl: Arch. f. Psychiat., 1911, 49, 406.

3. Schlesinger: Beiträge zur Klinik der Bückenmark und Wirbel-Tumoren, Jena, 1898. 
Sex and Age Incidence, and Rôle of Trauma.-It is curious that of 54 cases in Doerr's statistics, 46 were in males, 8 in females, and Schlesinger found a similar preponderance of males in all intramedullary tumors, the ratio being 4 to 1 . As to age, most of the cases have occurred in the first, third and fourth lecades, namely, 15, 14 and 16. respectively, out of 63 cases, the extremes of age being 8 months and 66 years. Trauma to the back seems to be an important factor in determining localization in the cord, and the same is true of severe attacks of acute infectious diseases, especially acute articular rheumatism and scarlet fever.

Symptomatology-The onset is usually with pain, paresthesias and weakness of one extremity, rapidly spreading to the other side, so the picture of a transverse lesion is produced. Pain usually precedes paralysis, except when the ventral horns are primarily affected. Dissociation of sensation with disproportionate affection of the temperature sense is frequent, but later all forms of sensation are usually affected. Muscular atrophies and vasomotor disturbances are common. Tenderness of the spine is not conmon but stiffness fairly common. The behavior of the reflexes naturally varies according to the region and tracts involved, the tendon reflexes of the legs ustually being increased with the disease at a level above the lumbar enlargement. When paraplegia has set in, sphincter disturbance is the rule. The course is progressive and rapid, the average duration being six to seven months. Death in most cases is caused by pulmonary or acute miliary tuberculosis; in others by sepsis from bed sores and infection of the urinary tract.

Prognosis.-The prognosis is extremely bad. I can find in the literature only one case report of recovery.

Treatment.-The one case of recovery referred to is reported from Switzerland by Veraguth and Brun, ${ }^{4}$ that of a man 32 years old, who had been treated for pulmonary tuberculosis four years prior to the onset of cord symptoms. The latter first consisted of stiffness and pain in the left side of the neck, followed by the development of a Brown-Séquard syndrome, with paralysis of the left extremities and anesthesia of the right ones. Two months later laminectomy in the neck was performed and a thickly encapsulated solitary tubercle measuring 17 by 11.5 by $9.5 \mathrm{~mm}$. removed from the interior of the cord on the left side. When the dura had been incised only a diffuse swelling of the cord was noted, but after incision of the pia the nodule was readily shelled out "like the yolk from a hard boiled egg." The

4. Veraguth and Brun: Cor. Bl. f. schweiz. Aerzte, 1910, 40, 1097. 
recovery was very rapid. Krauss and McGuire ${ }^{5}$ also report a case in which an intramedullary tubercle at the fifth thoracic segment was readily removed, but the patient died a few hours after the operation.

\section{REPORT OF CASES}

CASE 1.-Conglomerate tubercle in midthoracic region: Onset with epigastric paresthesia, then girdle pains, numbness and weakness of legs, finally picture of transverse lesion. Much pus in urine, but no pulmonary symptoms. Tuberculosis not recognized during life. Death seven months after onset. Necropsy: Pulmonary and genito-urinary tuberculosis. Conglomerate intramedullary tubercle at level of seventh thoracic vertebra. Numerous tubercle bacilli in sections from cord.

History. -A telephone lineman, aged 35 , was admitted to the service of Dr. Frank Billings in the Presbyterian Hospital, Jan. 6, 1916. I am indebted to Dr. Billings for the privilege of seeing and reporting the case. The family history was negative.

Previous History.-Measles and whooping cough in childhood; maxillary sinus infection on both sides four years prior to admission. The patient never had a trauma and gave no history of cough, fever, chills, sweats, abdominal pain or loss of weight.

Present Illness.-About Dec. 1, 1915, he began to notice a peculiar sensation in the epigastrium, which would disappear on rubbing the abdomen or walking. At first this sensation was only noticed on awakening. A few days later he noticed a girdle sensation and pain at the level of the lower ribs on both sides. In another few days this was followed by numbness in the sole of the right foot and rigid extension of the toes. After three or four days the numbness had reached to the knee and the left foot became similarly involved. December 22 the legs were so weak that he fell to the ground when he stepped from a wagon. The weakness progressed rapidly. December 24 he could still walk a little with the aid of a cane, but by January 2 he could not move the legs at all. By this time the numbness had ascended to the level of the costal margin on both sides. $\mathrm{He}$ also developed involuntary urination and obstinate constipation. When cathartics were given, involuntary defecation would result. There were occasional involuntary contractions and rigidity of the legs and twitching movements in the right lumbar muscles. Pain was not a prominent symptom, but there were occasional rather sharp, shooting pains radiating from the groins upward to the abdomen.

December 28 the patient was examined by Dr. L. F. McBride, whose chief findings were as follows: Spastic paralysis of both lower extremities with exaggerated knee jerks and bilateral ankle clonus. There was a saddle anesthesia and hypesthesia from the costal margin down. Blood: Wassermann reaction negative; red cells, 5,000,000; white cells, 10,000; hemoglobin, 87 per cent. Cerebrospinal fluid: Wassermann reaction negative; 30 cells per cubic millimeter; Nonne globulin test strongly positive. Urine: Albumin present; 30 to 40 leukocytes per cubic centimeter; a few hyaline and granular casts were found.

Condition on Admittance Jan. 6, 1916.-Complete paralysis of both legs. Loss of tactile and pain sense below the level corresponding to the eleventh intercostal nerve area, except that very slight tactile sensation remained on the inner surface of the thighs, soles of the feet and perineum. Sensation to heat and cold was also lost and there was complete loss of muscle sense in the legs.

The pupils and eye muscles were normal. The tonsils appeared diseased and the left one contained pus. Culture from the tonsil yielded hemolytic streptococci.

Examination of the lungs and heart was negative. The liver and spleen were not palpable. The abdomen was lax. There was no abdominal tenderness and

5. Krauss and McGuire: Jour. Am. Med. Assn., 1909, 53, 1911. 
nothing abnormal could be felt. January 6, blood examination: Red cells, 4,200,000; white cells, 7,200; hemoglobin, 80 per cent.; blood pressure, systolic, 150; diastolic, 100; urine, acid, with trace of albumin; numerous leukocytes, but no casts were found; temperature and pulse rate, normal.

Examination was made by me Jan. 14, 1916, when the following notes were dictated:

No voluntary movement in lower extremities. With the arms folded on the chest the patient can raise his head and shoulders slightly, and in making the

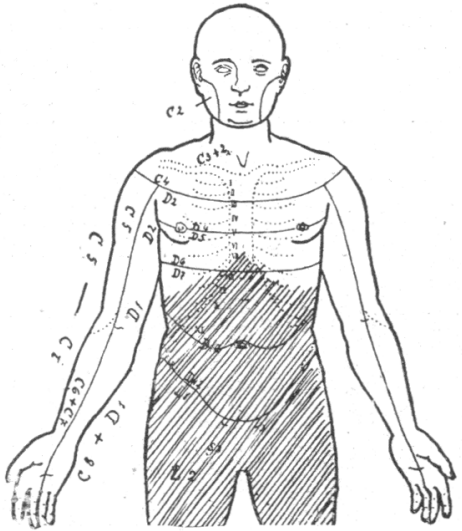

Fig. 1 (Case 1).-Sensory chart. The shaded portion indicates anesthesia to touch.

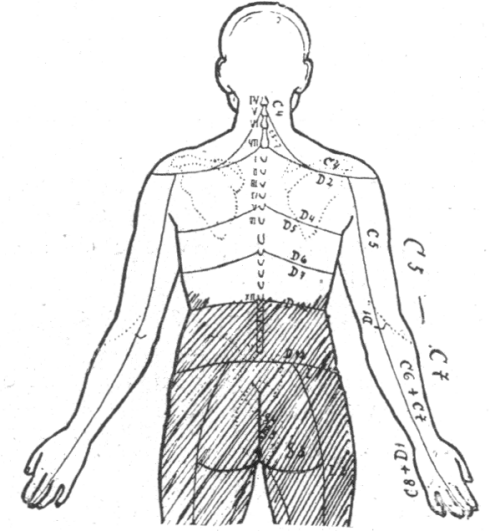

attempt the umbilicus moves 1 inch upward (Beevor's umbilicus sign). Abdominal reflexes not obtained, but on tapping the lower ribs, contractions in the oblique muscles are occasionally seen. The knee jerks are increased, with slight indication of clonus on the left side. Ankle jerks slightly increased. On stroking the soles of the feet slight extensor response of the big toe is obtained, together with a very marked "defense movement," consisting of flexion and adduction at the hip, flexion of the knee and extension at the ankle and slight flexion of the small toes. Direct myotatic irritability increased in the entire musculature of both lower extremities. Vesical sphincter much relaxed, as any movement

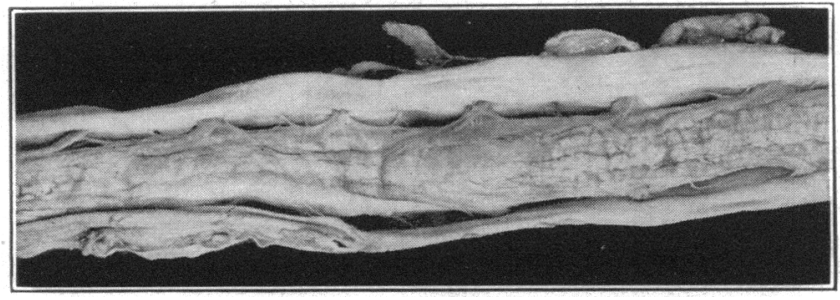

Fig. 2 (Case 1).-Fusiform enlargement of cord marking location of tubercle

is apt to cause dribbling of urine. Upward border of tactile anesthesia is at a level $1 \frac{1 / 2}{2}$ to 2 inches below the ensiform cartilage, that of analgesia 2 inches higher (Fig. 1). Pressure and muscle sense also lost in both legs. Diagnosis: Transverse lesion at about seventh or eighth thoracic segment; incomplete, as tendon reflexes are not abolished. Lesion probably intramedullary and of inflammatory nature, but pressure from without cannot be excluded even in the almost complete absence of pain.

Roentgen-ray examination of the spine was negative. Lumbar puncture, January 24 , yielded a clear fluid with a cell count of three; negative Wassermann 


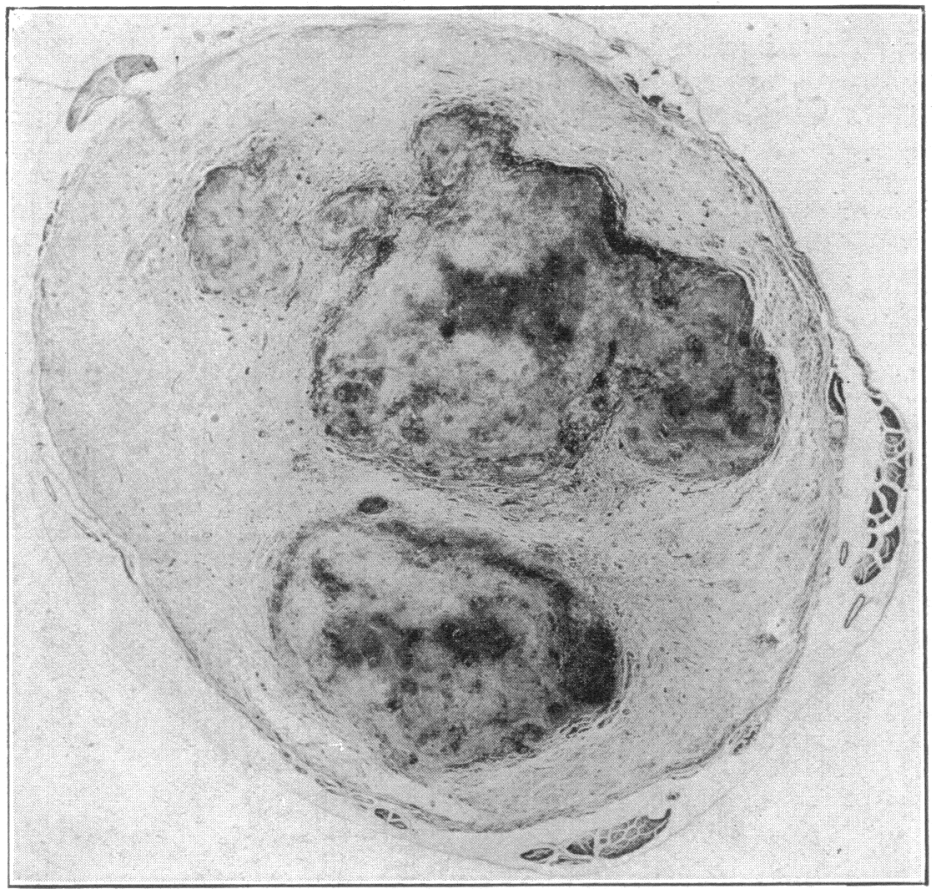

Fig. 3 (Case 1).-Cross section of conglomerate tubercle of cord showing two large caseous areas.

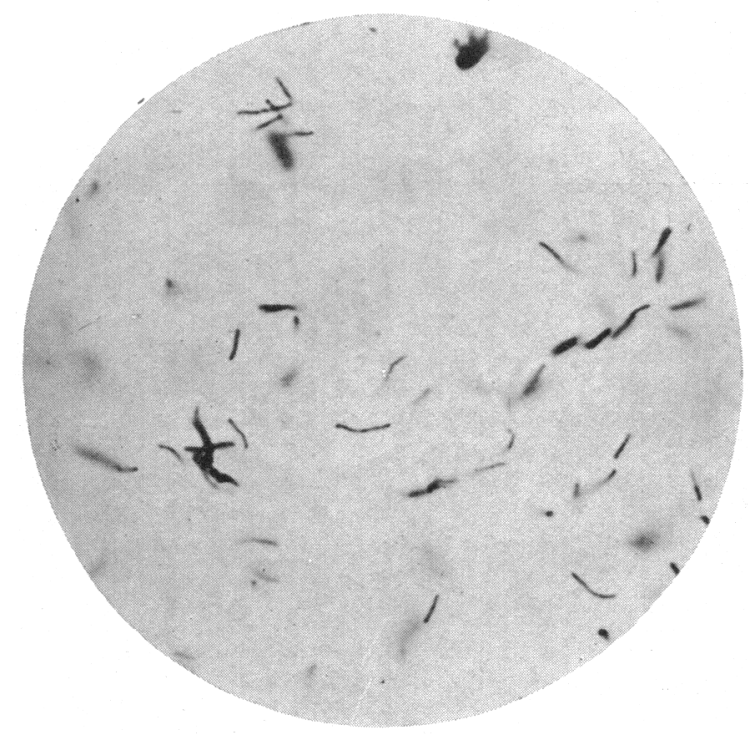

Fig. 4 (Case 1).-Tubercle bacilli in the cord. Carbolfuchsin. 
test; positive Nonne-Apelt globulin test. The Lange colloidal gold test was peculiar, no tube showing a change except the fifth (the dilution 1 to 160), which gave a definite reaction, the formula being 0000200000 .

February 17 the tonsils were removed; streptococci were obtained in culture.

From this time on there was no material change in the nervous findings. The urine always contained much pus and the bladder was repeatedly irrigated with boric acid or protargol; later also with argyrol. There was an irregular fever, the temperature varying between subnormal and $102 \mathrm{~F}$. The patient gradually grew weak and emaciated. No pulmonary symptoms attracted attention. The patient died July 25, 1916.

Necropsy.-The necropsy was held by Dr. B. O. Raulston, resident pathologist of the hospital, and the following anatomic diagnosis was recorded: Acute diffuse miliary tuberculosis of both lungs; chronic tuberculosis of the upper lobes of both lungs; extensive ulcerative tuberculosis of the left kidney; left perirenal abscess; nodular tuberculosis of the rigint kilney; tuberculosis of both ureters,

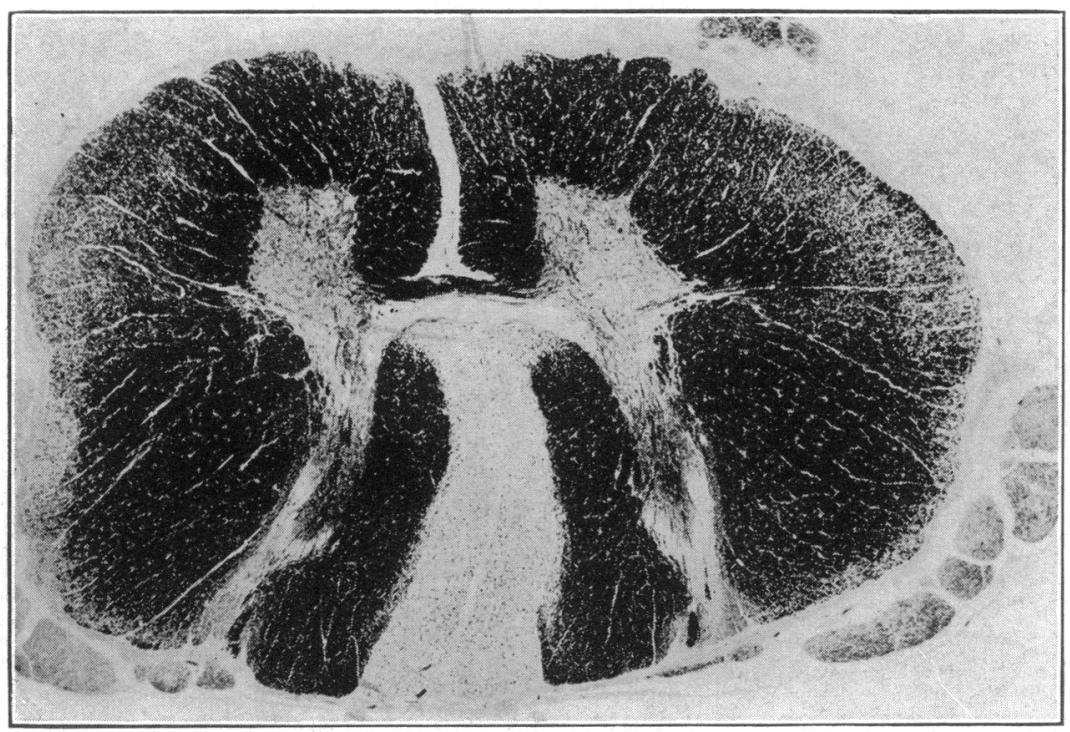

Fig. 5 (Case 1).-Ascending degeneration above level of tubercle. PalWeigert method.

urinary bladder, prostate and seminal vesicles; fistula between urinary bladder and rectum; tuberculosis of the spinal cord at the level of the seventh thoracic vertebra; marked shortening of the flexor muscles of both thighs; calcified tracheobronchial tuberculons lymph adenitis; marked anemia and emaciation; severe decubital necrosis; moderate hyperplasia of the spleen; cloudy swelling of the liver and myocardium; petechial hemorrhages on the gastric mucosa; hyperemia of the lining of the trachea and main bronchi.

The spinal column showed no change. The brain could not he examined.

Description of the Cord.-The dura shows no change except a fusiform bulging in the midthoracic region. It is also smooth internally and not adherent. The pia is slightly thickened and opaque in the thickened area, which mcasures $3 \mathrm{~cm}$. in length (Fig. 2). The greatest width of the cord in this portion is $13 \mathrm{~mm}$., while above anci bolow it measures $10 \mathrm{~mm}$. No nodules are seen on the anterior surface, but posteriorly at the lower end of the thickened area, pinhead sized grayish clcvations are seen along the posterior roots on the left 
side. On transverse section of the cord in the cervical region the columns of Goll are distinctly gray. In the lower thoracic and lumbar regions the lateral columns on both sides are distinctly gray.

In cross section of the thickened portion of the thoracic cord no trace of normal markings remain. About four fifths of the cross section is taken up by a firm, grayish-white tissue. Small wedge-shaped rests of cord tissue are seen near the median line anteriorly and on each side in the posterior horn region, posteriorly. Of the latter the left one is the larger. A section $1 \mathrm{~cm}$. farther down shows only remnants of cord tissue in a half dozen places along the periphery-each not over $1 \mathrm{~mm}$. in thickness.

Histologic Examination.-Cross section of the fusiform enlargement of the cord shows typical caseous tuberculosis (Fig. 3). All trace of the normal cord markings, even of the sulci, is lost. There are two large caseous masses sur-

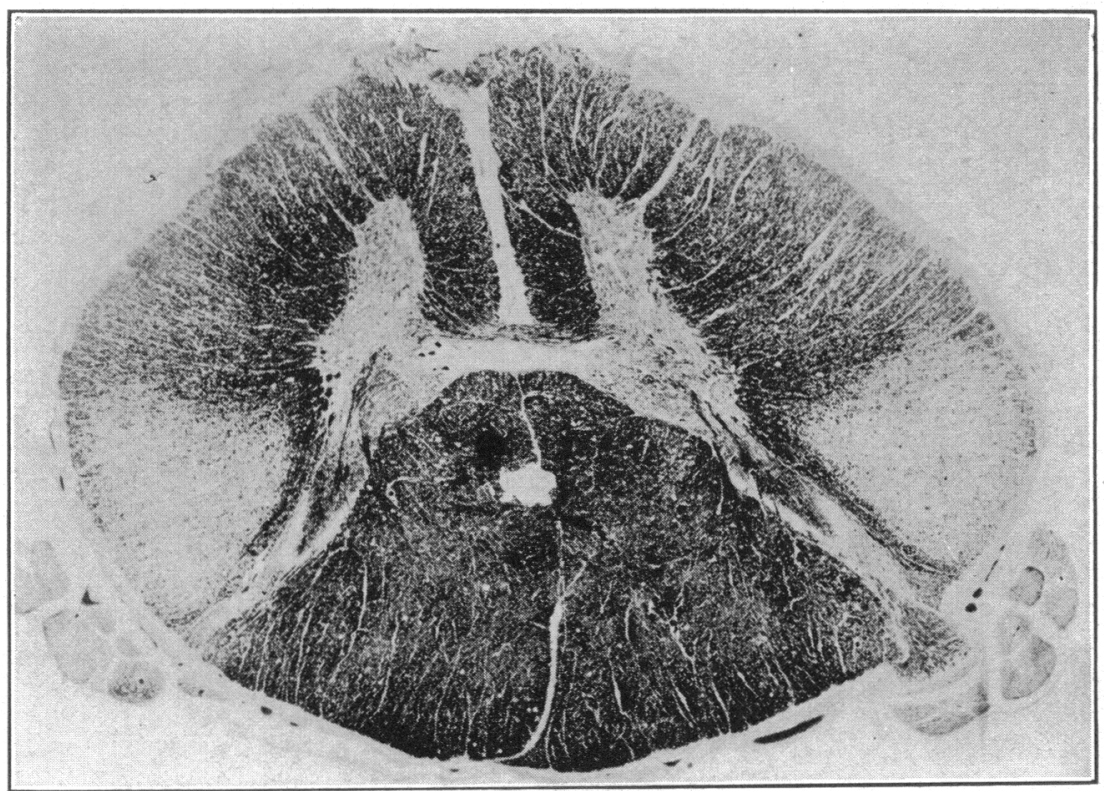

Fig. 6 (Case 1).-Descending degeneration below level of tubercle. PalWeigert method.

rounded by typical tuberculous tissue, rich in giant cells. Tubercle bacilli are extremely abunclant in this tissue (Fig. 4).

Sections of the cord above and below the fusiform enlargement show only ascending and descending degeneration, most clearly seen in Pal-Weigert preparations (Figs. 5 and 6 ), but it is sufficiently recent to give excellent Marchi reaction as well.

\section{COMBINED DFgENERATION OF THE CORD CALSED BY} VISCERAL TUBERCLLOSIS

There exists in the literature reports of a fair number of cases of combined degeneration of the cord similar to that of pernicious anemia in which tuberculosis of various parts of the body outside of the 
central nervous system seems to be the cause of the degeneration. The earlier literature is fully considered by Réné Sand, ${ }^{6}$ who also reports a case of his own. Henneberg, ${ }^{7}$ in his exhaustive article on "funicular myelitis" or "combined pseudosystemic degeneration" and "anemic focal leukomyelitis" comments on the relatively great rarity of such cord degeneration in connection with tuberculosis.

The following case appears to be one of this kind, though rendered more difficult and complicated by an old brain lesion apparently having no connection with the final illness.

CASE 2.-Man of 46 years with history of stroke causing right hemiplegia five years before death. Only partial weakness left behind. Later, pain and weakness of right side, followed by paraplegia and sphincter disturbance. Increased tendon reflexes and Babinski sign. No pulmonary symptoms and only slight physical signs. Nccropsy: Chronic pulmonary and pleural tuberculosis. Atrophy of brain and cord. Old hemorrhagic softening in left hemisphere. Nodule in left Sylvian fissure. Extensive bilateral cord degeneration.

History.-A telegraph operator, 46 years old, was admitted to my service in the Presbyterian Hospital, April 29, 1915. The family history was negative as to tuberculosis.

Previous IHistory.-Gonorthea at 25; chancre denied; moderate user of alcohol. Eight years previously he had a severe cough for a month. Following this he had occasional frontal headaches and frequent dizziness for two years. After a week of much headache and dizziness he had a stroke in March, 1910. He was unconscious one day. The right arm and leg were paralyzed and he also had considerable pain in the right extremities. The speech was not affected, at least not to any marked degree. He walked again in three weeks, but some degree of weakness and occasional pain in the right side remained.

Last Illness.-For over a year prior to admittance there had been numbness and more pain and weakness in the right arm and leg. Following an operation for hernia and hemorrhoids in February, 1915, he grew weaker and entered the hospital in April on account of general weakness and the annoying sensations on the right side.

Examination on Admittance, April 29, 1915.-Weight, 150 pounds; pupils react to light and in accommiodation; slight weakness of left internal rectus; grip in right hand slightly weaker than left; strength in legs about equal; moderate incoordination of hands and feet, more so on right side; wrist, elbow, knee and ankle reflexes brisk and equal; abdominal and cremasteric reflexes present, but weak on the left side; plantar reflex normal; no definite sensory disturbance; only slight lung findings, namely, relative dulness and mixed inspiration with bronchial expiration over left upper lobe; slight irregularity of heart action. Blood examination: hemoglobin, 87 per cent.; erythrocytes, $4,010,000$; leukocytes 10,400 . Urine negative except for a few pus cells. Wassermann test with blood and spinal fluid negative. The latter gave a cell count of 3 and negative Nonne-Apelt and Lange tests.

The patient remained in the hospital for three weeks and had normal temperature, pulse and respiration. He left the hospital, May 18 and returned Oct. 21,1915 , in a much worse condition. In June an abscess formed over one of the lower ribs anteriorly. This was incised and the patient had to stay in bed for a month. Afterward he was barely able to stand up and could not

6. Sand, Réné: Acad. roy. de méd. de Belg., Oct. 31, 1903.

7. Henneberg: Handbuch der Neurologie (Levandowsky), 1911, 2, 769. 
walk without help. The legs grew weaker but the pains were less troublesome than before. The fingers of the right hand became so numb and weak that he no longer could write. Slowness of micturition and occasional incontinence of urine and feces developed about three weeks before his return to the hospital.

Examination Oct. 21, 1915.-Marked general weakness and pallor; pupils react normally; weakness of left internal rectus; at 2 feet he could get binocular fixation with effort and retain it until a 5 inch point was reached, then the eye diverged. (lixamination by Dr. E. V. L. Brown.) No gross limitation of visual fields; no nystagnus; no other cranial nerve weakness. Right arm slightly but distinctly, weaker than the left one, with consiclerabie muscular rigidity,

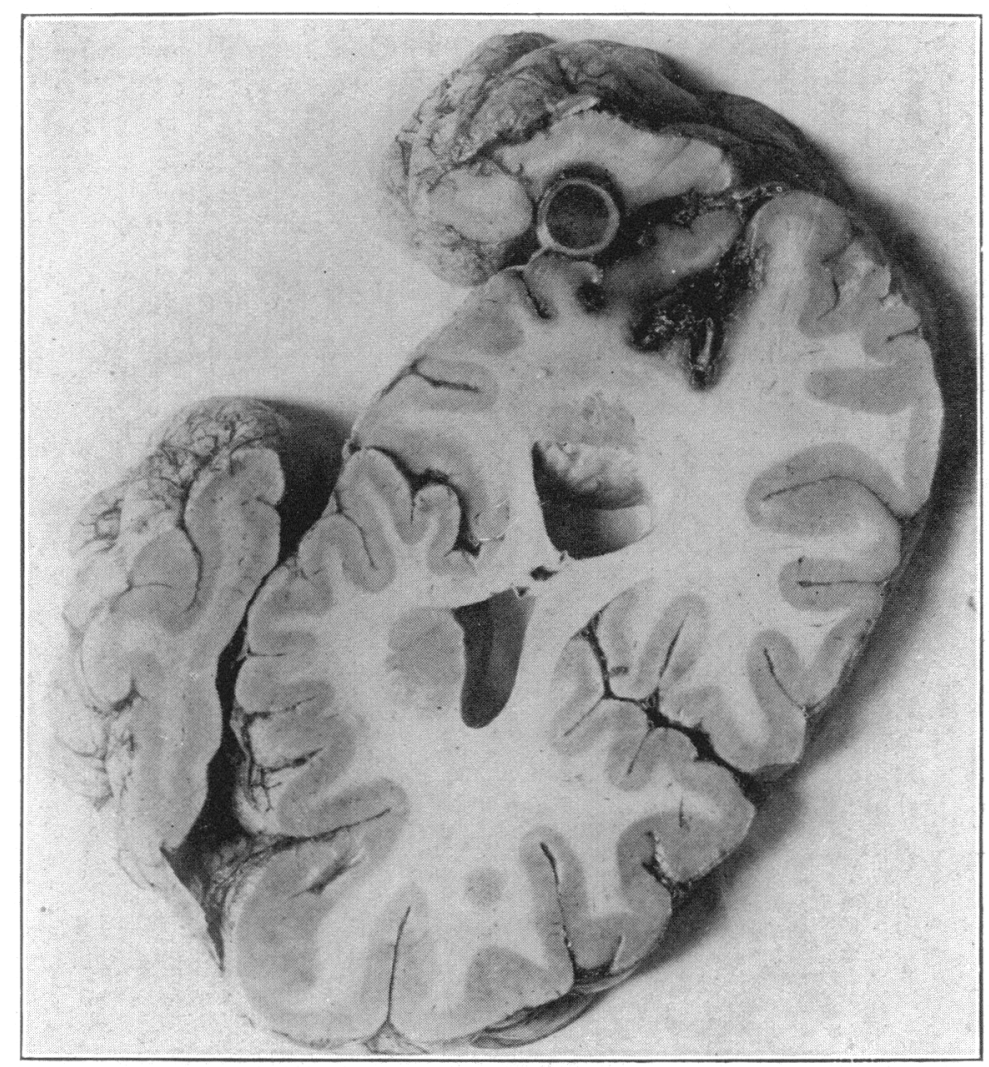

Fig. 7 (Case 2).-Old brain lesions; hemorrhagic cyst in Sylvian fissure and hemorrhagic softening in insula.

especially above the elbow; considerable ataxia of both arms; more so of the right one. The patient could raise the head from the pillow but could not raise himself to a sitting position. The right thigh could be flexed on the abdomen with the heel clragging on the bed, but he could not lift the foot. Extension and adduction of the right hip were fair; abduction very weak. The knee could be extended when the thigh was supported; ankle movements fair; extension of toes weak. Left leg: Flexion of thigh as weak as on the right side, but abduction and adduction better. The heel could not be lifted from the bed unless the thigh was supported; ankle and toe movements fairly good. 
Reflexes: Wrist reflexes present and equal; elbow reflexes increased, more so on the right side; abdominal reflexes not obtained; knee and ankle reflexes increased, more so on the right side; bilateral knee clonus present, but no ankle clonus; bilateral Babinski sign. Sensation: Tactile sensation lost below level of umbilicus; pain sense diminished below same level and temperature sense lost in both legs, but not on the abdomen; thorax rather hypersensitive.

The Wassermann test with the blood and spinal fluid and other tests on the latter were repeated and again reported negative. The luetin test also was negative. Hemoglobin, 66 per cent. ; erythrocytes, 3,520,000; leukocytes, 6,300. Blood pressure: Systolic 100; diastolic 60 . The urine contained numerous leukocytes and continued to do so. The sinus at the site of the old abscess reopened. Examination of the pus for tubercle bacilli was negative and the roentgen-ray examination revealed no bone lesion. The tuberculin test with $1 \mathrm{mg}$. of old tuberculin was negative; with $3 \mathrm{mg}$. the temperature rose to 100.2 $F$., and pain, tenderness and a little redness at the point injected were observed.

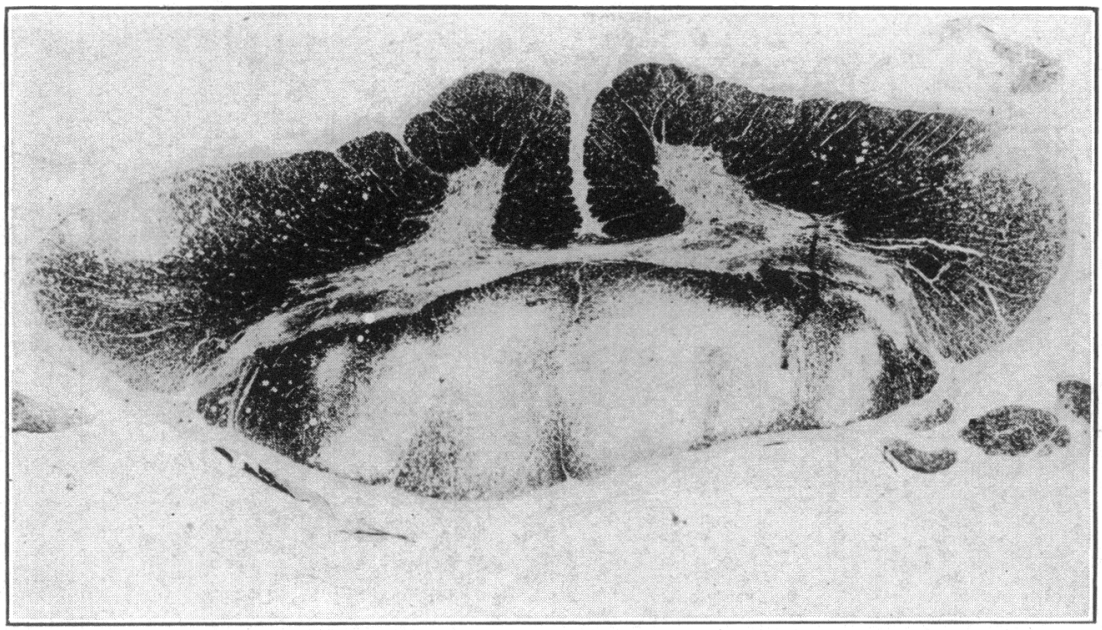

Fig. 8 (Case 2).-Thoracic cord. Degeneration in posterior and lateral columns. Pal-Weigert method.

The temperature occasionally rose to $100.5 \mathrm{~F}$, and this rise was ascribed to the cystitis. The catheter had to be used every day. The patient gradually failed and died Dec. 19, 1915.

Necropsy.-The necropsy was held by Dr. Raulston. The chief findings were: moderate edema of the brain; general atrophy of the spinal cord ; calcified plaque in spinal meninges; nodular caseocalcareous tuberculosis of the apex of the left lung; fistulous opening in the right lateral chest wall; right fibrous obliterative pleuritis; localized left fibrous pleuritis; calcified tubercles of tracheobronchial lymph glands; cloudy swelling of heart muscle; slight fatty changes in the lining of the aorta; passive hyperemia and cloudy swelling of kidneys; chronic purulent cystitis; passive hyperemia, fatty changes and cloudy swelling of the liver; tumor of right adrenal; passive hyperemia and hyperplasia of the spleen; petechial hemorrhages of the renal pelves.

The spinal cord and its dura weigh $30 \mathrm{gm}$. The dura shows little change; here and there slightly raised patches in inner surface and some roughening, but no thickening at point of contact with calcareous patch in arachnoid. This patch is situated along the posterior surface of the lower thoracic cord at approximately the sixth to eighth thoracic segment. It is $2.3 \mathrm{~cm}$. Iong by $1 \mathrm{~cm}$. 
in greatest wiclth and from 0.5 to $1.5 \mathrm{~mm}$. in thickness. It is whitish, rough and of bony hardness. It is adherent to the dura. No other calcified areas are found and the pia arachnoid proximal to this area shows marked fibrous thickening and is grayish-white in color. The condition is most marked in the midthoracic region and gradually diminishes upward. The pia of the anterior surface has a normal appearance. The size and contour of the cord are normal only in the lumbar and sacral regions, where the gray horns are distinct. In the thoracic region below the calcified region the cord is flattened anteroposteriorly; $1 \mathrm{~cm}$. below calcified patch the cord measures $1.2 \mathrm{~cm}$. laterally and $5 \mathrm{~mm}$. anteroposteriorly. The structure cannot be made out on cross section, which appears as an irregularly mottled gray and white surface. The same condition exists in the remainder of the thoracic region, although in the upper part the section shows a little more semblance of normal marking. The cervical region is markedly atrophic and even at the site of the cervical enlargement it is

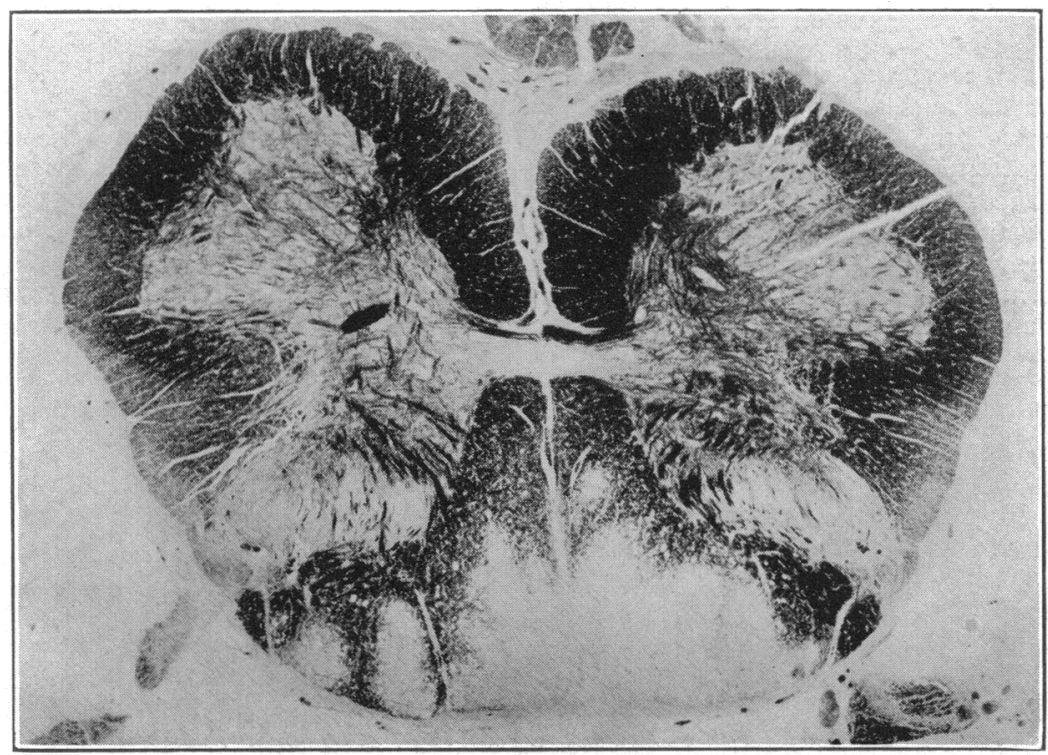

Fig. 9 (Case 2).-Lumbar cord. Degeneration mainly in posterior columns. Pal-Weigert method.

smaller than the lower thoracic and proportionately very much smaller than the lumbar portion. Brownish hemorrhagic and grayish-yellow degenerated areas are seen on the cut surfaces. The gray horns can scarcely be made out even in the upper cervical region. The bulb appears normal externally and on section.

The brain after formalclehyd hardening weighs $1.050 \mathrm{gm}$.

The dura shows no change. The pia over the convexity, especially in the vicinity of the paracentral lobules shows a fibrous thickening. more so on the left side. No other external change. On sectioning the brain shows an area of old softening in the right frontal lobe, which extends inward from the middle of the lateral border over half way to the lateral ventricle. It largely occupies the cortex, involves the insula and almost reaches the fissure of Sylvius. Just inferior to the area described the fissure of Sylvius contains a firmly adherent, smooth, oblong, grayish-white nodule which is about $1.5 \mathrm{~cm}$. long 
and $1 \mathrm{~cm}$. in diameter. On section it has a firm whitish wall $1.5 \mathrm{~mm}$. thick containing reddish-brown solid material (see Fig. 7). The cortex along the fissure of Sylvius shows superficial softening and brownish discoloration for some distance backward. In the left parietal lobe underneath the pia thickening described there is slight superficial softening. No other changes are found on the cut surfaces.

Histologic Examination.-Brain: The old focus of softening only shows pial fibrous thickening, destruction of cortex and replacement by a loose fibrous tissue with deposits of pigment. The nodule in the fissure of Sylvius has a hyaline, lamellated, fibrous wall, with small calcified areas. The contents are largely a hyaline mass with numerous slits (cholesterin ?) and granular masses suggestive of altered red blood cells. The vessels in the adjacent pia show fibrous thickening of the intima.

Spinal cord: The dura near the calcified plaque consists of only old fibrous tissue.

Weigert-Pal specimens show fairly symmetrical degeneration at all levels, involving chiefly the columns of Goll and Burdach and the tract of Gowers, but the crossed pyramidal tracts are also involved (Figs. 8 and 9). In the lumbar region the posterior roots show moderate degeneration. In the upper cervical region the small size of the cord is particularly striking; here the direct pyramidal tracts are much more degenerated than the crossed ones and the posterior roots show distinct degeneration. In the bulb the pyramids are normal but the degeneration of the posterior columns extends up to their nuclei. Hematoxylin-eosin and Van Gieson specimens only bring out the usual cribriform structure of the degenerated tracts and moderate thickening and hyaline change of the pial vessels.

30 North Michigan Avenue. 